\title{
Argentina Pereira Gomes: disseminação de "inovações" didáticas na educação primária na década de 1930
}

\author{
Argentina Pereira Gomes: dissemination of didactic \\ "innovations" in primary education school of the 1930s
}

Argentina Pereira Gomes: diseminación de “innovaciones" didácticas en la educación primaria em

la década de 1930

\author{
MáRCia Cristiane Ferreira MEndes (iDa \\ LIA MACHADO FIUZA FIALHO \\ Charliton José dos Santos Machado
}

Resumo

A educadora Argentina Pereira Gomes (1916 a 1962) foi normalista e professora de Língua Portuguesa. Lecionou para crianças e adolescentes na cidade de João Pessoa, Paraíba, nas principais escolas da capital: Grupo Escolar Epitácio Pessoa, Escola Normal, Liceu Paraibano, Escola Nossa Senhora das Neves. Questionou-se que formação educacional e ideias pedagógicas foram desenvolvidas por Argentina Gomes para que esta se constituísse uma educadora de relativa visibilidade na memória coletiva local, no segundo quartel do século XX. Objetivou-se compreender a trajetória formativa e profissional de Argentina Pereira Gomes, na interface com os seus métodos didáticos no contexto sócio histórico educacional da década de 1930, que lhe conferiram imortalidade no imaginário social. Desenvolveu-se uma pesquisa biográfica, amparada teoricamente na História Cultural, que utilizou fontes documentais - decretos, fotos, reportagens de jornal e revista - entrecruzadas com fontes orais coletadas por meio da história oral com 6 colaboradores. Constatou-se que Argentina Gomes era uma menina interiorana pobre com educação familiar patriarcalista e religiosa. Contudo, teve a oportunidade de migrar para capital e estudar na Escola Normal e, ao se formar professora, atuou nas principais instituições de ensino de João Pessoa, adotando os ideais de Pestalozzi, Froebel e,

\footnotetext{
a Universidade Estadual do Ceará (UECE), Fortaleza, CE, Brasil. Mestre em Educação, e-mail: marciacfmendes@gmail.com

b Universidade Estadual do Ceará (UECE), Fortaleza, CE, Brasil. Doutora em Educação, e-mail: lia_fialho@yahoo.com.br

c Universidade Federal da Paraíba (UFPB), João Pessoa, PB, Brasil. Doutor em Educação, e-mail: charlitonlara@yahoo.com.br
} 
posteriormente, da Escola Nova, disseminando-os ao escrever artigos na Revista do Ensino, descrevendo métodos didáticos ativos, uma inovação para o cenário educacional da época, marcado pela pedagogia tradicional.

Palavras-chave: Argentina Pereira Gomes. Biografia. Educação feminina. Escola primária.

\section{Abstract}

The educator Argentina Pereira Gomes (1916 to 1962) was a normalist and Portuguese Language teacher for children and teenagers in the city of João Pessoa, Paraíba, in the main schools of the capital: Epitacio Pessoa School Group, Teacher Training School, Paraíba High School, Nossa Senhora das Neves School. It was questioned which educational formation and pedagogical ideas were developed by Argentina Gomes, so this one has constituted an educator of relative visibility in the local collective memory, in the second quarter of century $X X$. The objective was to understand the formative and professional trajectory of Argentina Pereira Gomes, in the interface with her teaching methods in the historical social-historical context of the 1930s, which conferred immortality on the social imaginary. Biographical research was developed, supported theoretically in the Cultural History, which used documentary sources - decrees, photos, newspaper and magazine articles - intercrossed with oral sources collected by means of oral history with 6 contributors. It was verified that Argentina Gomes was a poor interior girl with patriarchal and religious family education. However, she had the opportunity to migrate to capital and study in the Teacher Training School and, when she was a teacher, she worked in the main teaching institutions of João Pessoa, adopted the ideals of the Pestalozzi and Froebel and later, of the New School disseminating them when writing articles in the Revista do Ensino, describing active didactic methods, an innovation for the educational scene of the time, marked by traditional pedagogy.

Keywords: Argentina Pereira Gomes. Biography. Female education. Primary school.

\section{Resumen}

El educador Argentina Pereira Gomes (1916-1962) fue normalista y profesor de la enseñanza del idioma portugués para los niños y adolescentes en la ciudad de João Pessoa, Paraíba, en las principales escuelas de la capital: Grupo Escuela Pessoa, Escuela Normal, Liceo Paraibano, Escuela Nuestra Señora de las Nieves. Se cuestionó que formación educativa e ideas pedagógicas fueron desarrolladas por Argentina Gomes para que ésta se constituyera una educadora de relativa visibilidad en la memoria colectiva local, en el segundo cuartel del siglo XX? Se objetivó comprender la trayectoria formativa y profesional de Argentina Pereira Gomes, en la interfaz con sus métodos didácticos en el contexto socio histórico educativo de la década de 1930, que le conferían inmortalidad en el imaginario social. Se desarrolló una investigación biográfica, amparada teóricamente en la Historia Cultural, que utilizó fuentes documentales - decretos, fotos, reportajes de periódico y revista - entrecruzadas con fuentes orales recogidas por medios de la historia oral con 6 colaboradores. Se constató que Argentina Gomes era una niña interiorana pobre con educación familiar patriarcalista y religiosa, sin embargo, tuvo la oportunidad de migrar a capital y estudiar en la Escuela Normal y, al formarse profesora, actuó en las principales instituciones de enseñanza de João Pessoa, adoptó los ideales de Pestalozzi y Froebel y posteriormente, de la Escuela Nueva 
diseminándolos al escribir artículos en la Revista de la Enseñanza, describiendo métodos didácticos activos, una innovación para el escenario educativo de la época, marcado por la pedagogía tradicional.

Palabras clave: Argentina Pereira Gomes. Biografía. Educación femenina. Escuela primária.

\section{Introdução}

A pesquisa em tela ${ }^{1}$ se insere no campo da História da Educação por trabalhar na interface de duas áreas coextensivas: a Educação — ao ensejar luz às práticas didáticas, vivências educativas e correntes pedagógicas — e da História — no que concerne aos estudos biográficos e análises de contextos sociais e culturais ao longo dos tempos, especialmente, na interligação com o cenário educacional da mulher no segundo quartel do século XX. Desenvolver pesquisas nessa seara "não se constitui uma tarefa simples por demandar conhecimentos amplos e interdisciplinares, em especial acerca da Educação e da História, na interface com aspectos políticos, econômicos, sociais, culturais, dentre outros" (LOPES, FIALHO, MACADO, 2018). Entretanto, tais estudos possibilitam interpretações da realidade sem perder o foco de que o conhecimento acadêmico é constitutivo de intencionalidade histórica (CHARTIER, 1988), ou seja, a busca por narrar eventos verdadeiros, que têm o homem por ator (VEYNE, 2008), se constitui um ideal inalcançável, mas passível de narrativa científica e crítica que colabora para a compreensão histórica das nuances educacionais. Este estudo, todavia, versa sobre a biografia de Argentina Pereira Gomes com ênfase na sua formação e prática docente, sem pretensão de uma suposta neutralidade na pesquisa, mas com o compromisso ético e científico de produzir uma narrativa o mais aproximado possível da realidade dos acontecimentos.

Argentina Gomes foi selecionada para ser biografada por sua longa contribuição para a educação paraibana, ao atuar por mais de trinta anos em

\footnotetext{
${ }^{1}$ Esse artigo foi elaborado a partir de uma pesquisa de mestrado realizada no Programa de PósGraduação em Educação da Universidade Federal da Paraíba intitulada "Memórias e Práticas Educacionais da Educadora Argentina Pereira Gomes: o seu legado no cenário educativo da Paraíba (1916 - 1962)". Ver mais em: https://repositorio.ufpb.br/jspui/handle/tede/4699
} 
importantes instituições escolares da cidade de João Pessoa, na Paraíba — Liceu Paraibano, Escola Nossa Senhora das Neves e Grupo Escolar Epitácio Pessoa -, participando diretamente da formação educacional de uma geração de crianças, na educação primária, bem como por ter disseminando ideias pedagógicas e práticas didáticas inovadoras na década de 1930; delimitação temporal elegida por ser o período em que ela consolidava a vivência de novas didáticas educativas e iniciava a escrita de artigos em revista para difusão de tais práticas.

Imagem 1 - Foto da biografada Argentina Pereira Gomes

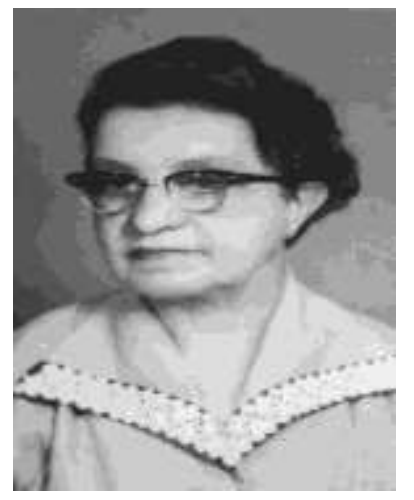

Fonte: Arquivo pessoal de Análice de Miranda Peregrino.

Importa destacar que o desenvolvimento da biografia de Argentina Gomes, na articulação indissociável entre o individual e o coletivo - o micro e o macrossocial —, permite lançar luz às questões subjetivas e pessoais na interação com o contexto sócio-histórico e educacional mediante análises minuciosas (DOSSE, 2015). Logo, se distancia dos estudos biográficos marcados por uma idade heroica e modal, pois se desprende das hagiografias e dos "heróis nacionais" e se insere na era das "idades hermenêuticas que concebem todos os indivíduos como sujeitos de história” (FIALHO, SÁ, 2018, p. 173). Longe da visão linear e teleológica proposta pelos primeiros estudos biográficos, esta biografia, assim como as novas análises historiográficas, preocupa-se em evidenciar a “[...] dialética entre acontecimentos, conjunturas e estruturas, elites e massas, indivíduos e grupos, palavra e ação" (LORIGA, 2011, p. 139). 
As biografias de educadoras são importantes porque permitem refletir hermeneuticamente a diversidade de professoras em suas particularidades, “considerando a história das práticas e as representações educativas que fomentam a trajetória docente de maneira contextualizada" (FIALHO, QUEIROZ, 2018, p. 71), inclusive possibilitando ampliar a compreensão de aspectos culturais e sociais que constituem a interface entre a vida individual e coletiva (NUNES, 2008).

A problemática que motivou o desenvolvimento da pesquisa foi: Que formação educacional e ideias pedagógicas foram desenvolvidas por Argentina Gomes para que esta se constituísse uma educadora de relativa visibilidade na memória coletiva local, no segundo quartel do século XX? Para desvelar essa inquietação, desenvolveu-se uma pesquisa com o objetivo de compreender a trajetória formativa e profissional de Argentina Pereira Gomes, na interação com os seus métodos didáticos no contexto sócio-histórico educacional das décadas de 1930, que lhe conferiram imortalidade no imaginário social. Para alcançar esse escopo, delinearam-se dois objetivos específicos, quais sejam: descrever a trajetória de formação educacional e profissional de Argentina Pereira Gomes; e compreender que práticas consideradas inovadoras eram adotadas e disseminadas na atuação docente de Argentina Gomes no cenário sócio-histórico educacional da cidade de João Pessoa, na década de 1930.

Parte-se da hipótese de que mesmo numa época marcada pela educação familiar patriarcalista, que fomentava educação feminina voltada para as prendas do lar e para o matrimônio, Argentina Pereira Gomes rompeu com práticas tradicionais do ensino formal na condição de professora, adotando métodos inovadores, e tecendo críticas pertinentes às características da pedagogia tradicional.

É oportuno salientar que a Paraíba, na década de 1930, ainda tentava sistematizar seu processo de ensino, assim como os demais estados do Brasil, não obstante, a influência no tocante à renovação dos métodos de ensino incentivados por intelectuais como Fernando de Azevedo, Lourenço Filho, Anísio Teixeira, dentre outros ${ }^{2}$, impulsionando o Movimento da Escola Nova, não havia alcançado

\footnotetext{
2Sampaio Dória - São Paulo, 1920; Lourenço Filho - Ceará, 1922; Augusto Bezerra de Menezes - Rio Grande do Norte, 1924; Anísio Teixeira - Bahia,1925; Lisímaco Costa - Paraná, 1927; Fernando de Azevedo - Distrito Federal, 1927 (SAVIANI, 2008).
} 
os objetivos desejados nas escolas brasileiras (FREITAS; BICCAS, 2009) e a maioria dos professores mantinham posturas e práticas tradicionais estáticas e inalteradas na primeira metade do século XX. Em João Pessoa, não diferente, as atividades ainda eram mecanizadas e desvinculadas da realidade, apresentando distanciamento dos pressupostos da Escola Nova (MENDES, 2012).

De acordo com Saviani (2008), a concepção escolanovista foi construída sob a crítica da escola tradicional, pois a escola, como instituição formadora, deveria ser capaz de corrigir as distorções sociais expressas pelo problema da marginalidade. Tendo a educação como redentora, com efeito, na prática, a educação primária na Paraíba da década de 1930 era essencialmente tradicional, mnemônica e reprodutora. Nesse cenário educacional, além de "rainha-do-lar" — mãe, dona de casa e esposa subserviente - a educação feminina era voltada para a mulher como "pedagoga do lar", aquela que recebeu a função de educar os filhos e conservar a família sob parâmetros de subserviência à figura masculina, do pai e marido (OLIVEIRA, 2002).

Dissipava-se também "o discurso voltado à regeneração dos hábitos e à propagação da higiene, consolidando um saber pautado nas reformas morais e físicas [...], que foram largamente propagadas na imprensa nas décadas iniciais do século XX” (VASCONCELOS, FIALHO, MACHADO, 2017). Afinal, uma população desnutrida e doente era entrave para consolidação de uma sociedade que se propunha vigorosa, voltada aos desafios do progresso, o que demandava adotar preceitos sanitaristas, que disciplinavam hábitos cotidianos - de moradia, alimentação, higiene, vestuário (MATOS, 2010). Com efeito, a estratégia de higienização das cidades do Estado Moderno “esbarrava, frequentemente, nos hábitos e condutas que repetiam a tradição familiar e levavam os indivíduos a não se subordinarem aos objetivos do governo" (SILVA, 2006, p. 86).

O desenvolvimento da biografia de Argentina Pereira Gomes, reconstituindo modelos formativos e práticas pedagógicas na interação com o contexto históricoeducacional, se configura relevante, pois permite, além da preservação e ampliação, a compreensão da história da educação, ao lançar lume à participação feminina na historiografia, por vezes relegadas aos porões da memória. O exercício da pesquisa biográfica de Argentina Gomes, na ação de narrar uma vida, envolveu um trabalho 
micro-histórico ao caracterizar e personalizar um sujeito na sua relação indissociável com o todo, vasto e complexo, e permitiu ampliar a compreensão macro-histórica ao ensejar uma análise mais minuciosa que considera subjetividades e desvela minúcias irrefutáveis para a compreensão da historiografia (LORIGA, 2011) e, mais especificamente, da História da Educação.

\section{Metodologia}

A pesquisa do tipo biográfico fundamenta-se na História Cultural sob o prisma historiográfico ensejado pela terceira geração dos Analles, que proporcionou novas abordagens para as pesquisas no campo da História da Educação, ao proporcionar a ampliação acerca da compreensão sobre fonte histórica e passar a considerar todo o vestígio que conta a história do homem como fonte, sejam eles por meio de documentos escritos, imagéticos ou orais (BURKE, 1992, 2008, 2010). Assim, a História Cultural possibilitou valorizar os sujeitos e suas individualidades, independente de sua visibilidade social, permitindo vir à tona narrativas de grupos, por vezes, invisibilizados, tais como o de mulheres, por exemplo, lançando lume às nuances específicas.

Dialogou-se com a perspectiva biográfica, no sentido de produzir e valorizar a compreensão de uma vida na interação indissociável com o coletivo, considerando a relação intrínseca com o contexto social, cultural e educacional (DOSSE, 2015); foi possível desenvolver uma aproximação da realidade educativa da década de 1930, a partir da narrativa da vida de Argentina Pereira Gomes, com ênfase na sua trajetória formativa e profissional e nos métodos pedagógicos desenvolvidos. Afinal, "são significativas as biografias que, ao conseguir delinear as características individuais do biografado, apresentam uma relação dialética entre o contexto social e a atuação de aproximação ou distanciamento do indivíduo desse contexto" (LEITE, 1984, p. 12).

Interessa esclarecer que a pesquisa foi iniciada com uma busca livre no Google com o descritor "Argentina Pereira Gomes" e "Argentina Gomes", bem como nas principais bases de dados científicas - na Biblioteca Digital Brasileira de Teses e Dissertações - BDTD, na base de dados Scientific Eletronic Library Online — Scielo e 
no Portal de Periódicos do Centro de Aperfeiçoamento de Pessoal de Ensino Superior - CAPES, em novembro de 2018, na tentativa de localizar produções sobre a educadora Argentina Pereira Gomes. No entanto, nada foi encontrado nas bases científicas, além da pesquisa dissertativa que originou esse artigo. Já na busca livre no Google, há registro de uma homenagem concedida à biografada como patronesse de uma escola estadual ${ }^{3}$, localizada na cidade de João Pessoa - PB, o que expressa certo reconhecimento a Argentina Gomes, bem como sua relativa visibilidade social.

Posteriormente à investigação virtual, que em nada contribuiu para compreender a formação educativa e atuação educativa de Argentina Gomes, buscou-se levantar fontes documentais nos acervos das instituições de preservação da memória de João Pessoa, cidade onde a biografada se formou professora e atuou ao longo de sua vida, a saber: na Fundação Espaço Cultural (FUNESC), local em que se encontrou e considerou para a pesquisa reportagens do Jornal A União periódico da imprensa oficial da Paraíba - e um decreto oficial de nomeação de Argentina; no arquivo das Escolas Extintas da primeira região, onde foi identificado o relatório de inspeção permanente do Colégio Nossa Senhora das Neves, instituição em que a biografada atuou; na Fundação José Américo, onde nada foi encontrado sobre a biografada; no Instituto Histórico e Geográfico Paraibano (IHGP), no qual foram encontrados dois escritos deixados pela educadora, registrados na Revista do Ensino, intitulados: "Principios basicos do methodo didactivo", datado do ano de 1932 e "Língua materna", do ano de 1937. O primeiro esclarecia a prática de ensino de Argentina e transparecia a consonância de suas ideias e o último mencionava a importância da Língua Portuguesa e descrevia métodos de ensiná-la para promover um bom aprendizado.

Além das fontes documentais, também foram localizados alguns colaboradores, quais sejam: Haroldo Lucena, José Otávio de Arruda Melo e Linalda de Arruda Melo — ex-alunos da Argentina; João Pereira Gomes Filho e Maria Martha Dieckman — sobrinhos da biografada. Estes conviveram com a biografada

\footnotetext{
${ }^{3}$ A Escola Estadual Prof. ${ }^{\text {a }}$ Argentina Pereira Gomes foi oficializada pela Secretaria de Educação do Estado da Paraíba, pelo Decreto 10.013, ano de 1976 e autorizado o seu funcionamento pelo Conselho Estadual de Educação da Paraíba na resolução № 33/1982.
} 
no período em análise e aceitaram contribuir para fomentar o arcabouço de fontes orais da pesquisa por meio da História Oral (HOLANDA; MEIHY, 2007) consentida formalmente, mediante assinatura do termo de consentimento livre e esclarecido, no qual eram mencionados objetivos, riscos, ausências de benefícios, maneira de participação, etc.

As narrativas para fomentar as biografias propostas não se constituíram em relatos cronológicos e lineares previamente definidos como exemplos morais (LE GOFF, 2003), mas, ao contrário, permitiram visibilidade ao contexto em que a biografada estava inserida na interface com aspectos sociais e culturais que interferiram para emergência da formação educacional e práticas educativas difundidas por Argentina Gomes. Os documentos impressos entrecruzados com as fontes orais permitiram trazer à tona uma narrativa biográfica da educadora Argentina Pereira Gomes.

\section{Argentina Pereira Gomes (1894-1962): formação educativa e sua inserção no magistério}

Argentina Pereira Gomes nasceu na cidade de Carpina — PE, em 26 de janeiro de 1894 e era de origem humilde. Filha de João Gregório Pereira Gomes, profissional liberal, e de Carpitulina Pereira Gomes, dona de casa, conviveu com uma família numerosa composta ainda pelos irmãos Manuel Adolpho Pereira Gomes, Valfrido Pereira Gomes, Olímpio Pereira Gomes, João da Mata Pereira Gomes, Vital Pereira Gomes, Vitaliano Pereira Gomes, Carmelita Pereira Gomes e Jesuína Pereira Gomes (MENDES, 2012). Teve uma educação patriarcal permeada por ensinamentos religiosos - com base no catolicismo - e aprendizagens relativas a prendas do lar. Apesar da ausência de escolarização, seus pais valorizavam a educação feminina, com vistas a qualificar a moça para um bom matrimônio (FALCI, 2001).

Argentina Gomes residiu na cidade de Carpina por nove anos, migrando em 1903 com toda a família para a capital da Parahyba do Norte, pois seu pai buscava trabalho e melhores condições de vida, após a falência no trabalho, decorrente do envolvimento com jogos de azar (DIECKMAN, 2009). A permanência da família 
Pereira Gomes na Parahyba do Norte possibilitou, entre outras coisas, a consolidação educacional dos filhos, a exemplo de Argentina Gomes, que passou a estudar na tradicional Escola Normal do Estado, na qual concluiu os estudos em 1916, partindo em busca de um espaço profissional, numa sociedade em que as mulheres geralmente dependiam financeiramente dos pais ou do marido, privilegiando as atividades de dona de casa ou tarefas no âmbito privado (ALMEIDA, 2007).

João Pereira Gomes Filho infere que Argentina Gomes “abriu, desde cedo, o leque da intelectualidade na família", ao se inserir de maneira pioneira na profissão docente (GOMES FILHO, 2009). O início da profissionalização das mulheres no Brasil foi marcado pelo magistério na educação primária, profissão percebida pela sociedade como pertinente ao sexo feminino, por ser considerada extensiva ao lar, pelo fato de o feminino ser associado a características de afetividade e maternidade inata, o que lhe concedia aptidão para a educação das crianças pequenas, como leciona Saviani (2011, p. 222):

Se a educação deve formar a consciência moral do cidadão, então a mulher, zelosa protetora desses princípios no lar, é quem melhor pode estendê-lo aos jovens. Se existe a necessidade de se formar a nação, a mulher é o centro da unidade menor da sociedade, sobre a qual se assenta o edifício social. Se a educação trabalha com crianças, que dependem de carinho e cuidados especiais, então nada como a mulher! Estava aberto o caminho para a feminização da atividade escolar.

Argentina Gomes, não diferente de tantas outras moças das primeiras décadas do século XX que tiveram acesso à educação formal, realizou o curso normal na Escola Normal do Estado e, posteriormente, ocupou espaço profissional como professora de crianças (MENDES, 2012). Sua formação na escola normal foi marcada pela educação tradicional, na qual a aprendizagem se dava de maneira mnemônica com exercícios repetitivos e descontextualizados, centrada na figura do professor como detentor do conhecimento, que valorizava a disciplina, a obediência, a organização impecável e a submissão à autoridade do pai ou marido (LOURO, 2001).

Argentina Gomes se dedicou, especialmente, a lecionar língua portuguesa nas seguintes instituições de ensino: Escola em Borborema (nome desconhecido), Grupo Escolar Epitácio Pessoa, Escola Normal, Liceu Paraibano, Escola Nossa 
Senhora das Neves. Em 1916, conseguiu seu primeiro emprego em cidade do interior, foi nomeada como professora da cadeira mista do ensino primário na cidade de Borborema, no Brejo paraibano, cargo que exerceu até o ano de 1919, como se verifica no Decreto $\mathrm{N}^{\mathrm{o}} 55$ da Parahyba de 28 de janeiro de 1916: "O $1^{\circ}$ Vice-Presidente do Estado, de acordo com o $\operatorname{art}^{\circ} .25$ da lei no .412 de 9 de outubro de 1915, resolve nomear a professora normalista D. Argentina Pereira Gomes para reger a cadeira mista do ensino primário de Borborema, devendo solicitar seu título na Secretaria de Estado". Era relativamente comum que as professoras que passavam pela Escola Normal do Estado fossem direcionadas a exercer sua profissão, por pelo menos um ano, no ensino primário das cidades do interior da Paraíba; medida que tinha como objetivo melhorar a qualificação dos professores ao tempo que colaborava com a educação nos centros rurais do estado (PINHEIRO, 2006).

Após a sua experiência profissional no interior, Argentina Gomes regressa à capital em 1917, sendo, então, nomeada professora do Grupo Escolar Epitácio Pessoa, no qual permanece por oito anos (MENDES, 2012). No ano de 1928, ela participa do concurso público para a cadeira de Língua Portuguesa da Escola Normal, disputando a vaga com o advogado Demétrio de Toledo, galgando sucesso ao ser também aprovada.

\begin{abstract}
A banca examinadora classificou ambos os candidatos. E talvez até tivesse sentido uma dificuldade: - saber verdadeiramente quem levara mais vantagem; se o bacharel Demétrio de Toledo, perspicaz e culto, ou a professora Argentina Pereira Gomes, acentuadamente modesta, estudiosa, lúcida, que surpreendera a todos com magníficas provas (JORNAL A UNIÃO, 1962).
\end{abstract}

O ingresso conflituoso de Argentina Gomes na Escola Normal é explicado na entrevista de Analice de Miranda Peregrino, que enfatiza esse acontecimento como um marco na história da educação paraibana:

o fato mais importante era quando ela fez o concurso que não houve nem primeiro e nem segundo lugar, foi igual os dois subiram ao mesmo tempo, porque não podiam dar o segundo lugar a ela dado ao conhecimento e nem ao outro por ser homem (PEREGRINO, 2009).

Ou seja, em 1928, a ex-aluna da Escola Normal retorna na condição de professora concursada ao competir com um homem e demonstrar melhores resultados. Tal empreendimento, juntamente com a realização de um trabalho 
reconhecido pela comunidade normalista como muito qualificado, possibilitaram certo reconhecimento e abertura de outras oportunidades, como, por exemplo, a docência no recém-inaugurado Liceu Paraibano (OLIVEIRA, 2012). Para comprovar a presença de Argentina Gomes na referida instituição, recorreu-se às fontes orais dos seus ex-alunos, que lá concluíram o ginasial. Segundo José Otávio de Arruda Melo (2008), professor aposentado do curso de História, na Universidade Federal da Paraíba (UFPB):

Dona Argentina, quando eu peguei dona Argentina, eu entrei no Liceu em 1951 e saí em 1957. O Liceu só tinha praticamente duas professoras de português, ambas mulheres. Dona Argentina pegava o ginásio todo. Pegava do primeiro ano ginasial até o quarto ano. E em cima vinha dona Olivina Carneiro da Cunha.

Linalda de Arruda Melo, irmã do professor José Otávio, também aluna de Argentina no Liceu Paraibano, e professora do Curso de Letras na UFPB, acrescenta que foi Argentina Gomes que lhe "despertou interesse por história da língua, pela gramática histórica e pela literatura" (MELO, 2009). Dessa experiência foi possível perceber sua presença no Liceu Paraibano: "Então eu estudei o ginásio que equivale aos anos finais do ensino fundamental. Aqui era o secundário completo. É tanto que o Liceu só tinha a partir do ginásio” (MELO, 2009).

Argentina Gomes também lecionou no Colégio Nossa Senhora das Neves ${ }^{4}$, do qual só se desligou com seu falecimento em 1962. O relatório de inspeção permanente do colégio, assinado pelo Inspetor Monsenhor Manuel Maria de Almeida, no ano de 1943, atesta, inclusive, reconhecimento ao seu trabalho: "os professores Dr. Luiz Gonzaga de Albuquerque Burity, Oscar de Oliveira Castro, Argentina Pereira Gomes, são tidos como os mais competentes nas respectivas matérias de que são docentes".

Sua prática docente nas escolas pelas quais passou na década de 1930, com efeito, será explicitada no tópico que segue, embora suas opções didáticas não possam ser compreendidas destituídas da sua formação educativa, que perpassa pela

\footnotetext{
${ }^{4} 0$ Colégio Nossa Senhora das Neves foi criado em 1857, sendo uma instituição de ensino exclusivamente para mulheres; mais informações, consultar a dissertação de mestrado, defendida na UFPB, intitulada: Magistério em Declínio: histórias e memórias de ex-alunas do magistério do colégio Nossa Senhora das Neves (1970), de autoria de Santos (2009).
} 
educação católica e patriarcalista, oriunda de uma família humilde e conservadora que valorizava a educação e concebia o magistério como única opção para a mulher galgar independência financeira. Tal prática atravessa as instituições nas quais exerceu a docência com compromisso e responsabilidade, reconhecidos por seus pares e ex-alunos, o que oportunizou não apenas atuar na educação primária, mas também no ensino secundário, adotando ritmos e tempos próprios, valores, ideias, vivências e histórias, sendo assim, impossível separar o "eu profissional" do "eu pessoal" (NÓVOA, 1995, p. 17).

\section{Os métodos didáticos na prática educativa de Argentina Pereira Gomes}

Os textos escritos pela biografada na Revista do Ensino foram as principais fontes que trouxeram indícios acerca dos métodos didáticos adotados e propagados na sua prática educativa. O artigo publicado em 1932, intitulado: "Língua Materna", descreve a preocupação de Argentina Pereira Gomes sobre como estava sendo ministrado o Português nas escolas primárias:

O ensino da língua vernácula, em nossas escolas primarias, é, incontestavelmente, o ponto para onde deve convergir a atenção do professor e que exige de suas energias e de seu precioso tempo. Não temos aqui a pretensão de versar a matéria sob todos os seus aspectos. Nosso intento é, apenas, prestar um pequeno auxílio ao estudo da linguagem, valendo-nos para isso da experiência de alguns anos de magistério (GOMES, 1932, p. 5).

A partir de sua prática escolar e de sua preocupação com a educação primária, Argentina Gomes passa a sugerir uma "nova" didática de ensino voltada para o ensino do Português, considerando em seus escritos elementos que pudessem levar o aluno a aprender de forma significativa, dinâmica e contextualizada, inclusive, criticando métodos considerados enfadonhos baseados na memorização. Ela valorizava o desenvolvimento natural do aluno descrito por Pestalozzi, ao lecionar que o educador: "[...] a partir da natureza das próprias coisas e não por palavras; deixar que ele (aluno) veja, ouça, encontre as coisas, que caia e se levante de novo. Aquilo que pode fazer para si, que o faça, pois a natureza ensina melhor 
que os homens [...]" (GILES, 1987, p. 189). Afinal, ela acreditava que "toda a instrução devia seguir e estar em harmonia com as etapas que pautam o desenvolvimento da natureza humana" (GILES, 1987, p. 191). Consoante a tal postulado, Argentina Gomes escreveu "muito importa ao professor saber por onde o alumno começar e a ordem natural a seguir na acquisição dos conhecimentos” (GOMES, 1932, p. 5).

A busca por elementos concretos da realidade do aluno para se utilizar no fomento a uma aprendizagem que tivesse maior sentido na vida do estudante foi uma marca na didática de Argentina Gomes (MENDES, 2012). Ela postulava um processo de ensino em que o aluno pudesse assimilar os novos conhecimentos a partir dos que já tinham sido adquiridos, ou seja, considerando os conhecimentos prévios e as experiências de vida:

O menino leva para a escola sua linguagem familiar viva, interessante, fecunda. Aproveitamo-la, cuidadosamente, para ponto de partida de todos os ulteriores conhecimentos, subindo, gradativamente, até o nível intelectual do adulto (GOMES, 1932, p. 6).

Esse modelo de aprendizagem, que levava em conta as fases de desenvolvimento do aluno, seu ritmo individual de aprendizagem e os conhecimentos pré-existentes, contrariava a perspectiva de uma educação tradicional, descontextualizada, que considerava o aluno uma tábula rasa. Segundo Argentina Gomes (1932), a criança precisava ter motivação para aprender, que a levasse a desenvolver uma maturidade saudável sem necessidade de castigos ou coerção. Ela explica: "Evitemos, sobretudo, exigir da creança aquillo que é superior à sua inteligência atendendo que as grandes dificuldades arrastam vezes ao desanimo e à apathia" (GOMES, 1932, p. 6).

Segundo sua ex-aluna Linalda de Arruda Melo, Argentina Gomes possuía uma didática inclusiva, envolvente, que acreditava no potencial do aluno e considerava suas particularidades. Inclusive, exemplifica:

Ela sempre disse, tanto que ela nunca discriminava por assim dizer, o aluno atrasado, o aluno que tirasse nota baixa, o aluno que lesse mal, que lesse errado, sempre dava aquele estímulo. A gente via que ela dava aquele estímulo, não se mostrava decepcionada com o desempenho do aluno, mas estava sempre confiante, com esperança de uma melhora, então ela era a pessoa da esperança (MELO, 2009). 
Haroldo Lucena, outro ex-aluno, destaca, na educadora, "traços de uma pedagogia inovadora pela sua preocupação com a aprendizagem do aluno, colocando-o como centro do processo educativo". Lucena complementa inferindo que: "[...] castigo de maneira nenhuma! [...] pessoa muito compreensiva [...]", informando que a repressão e o autoritarismo não faziam parte de sua prática. E explica: "Na verdade metódica também, gostava das coisas certas, [...] mas não exigente àquele ponto de não permitir que as pessoas se mexessem na cadeira como era comum naquela época, o aluno podia interagir” (LUCENA, 2009). Esse método, denominado por Lucena de "pedagogia inovadora", era descrito por Argentina Gomes como "Pedagogia Objetiva”, em sua publicação na Revista Ensino:

\begin{abstract}
Em oposição à Pedagogia então dominante por toda a parte, que tinha em grande conta as abstrações, os conceitos, as regras e definições, surge a Pedagogia Objetiva verdadeiramente scientifica, fundada na observação, no estudo da creança, de suas inclinações, de seus gostos e de seus interesses. Esta se assenta sobre a intuição (GOMES, 1937, p. 62).
\end{abstract}

Chama a atenção o fato de Argentina Gomes ter sido formada nos moldes de uma educação tradicional, com forte intervenção religiosa, em meio a uma cultura conservadora e, na contramão do experienciado, propagar, no início da década de 1930, “didáticas inovadoras" tão distintas das adotadas pela maioria dos seus pares professores nas escolas tradicionais onde lecionava. Importa destacar que a educadora não costumava fazer menção a quaisquer ensinamentos de cunho religioso, valorizava um ensino dialógico desde experiências concretas: “[...] ser ministradas por meio de palestras agradáveis e leves, onde o mínimo seja levado a observar, formar phrases, descrever objetos usuaes, tirar conclusões, práticas, conversar, enfim" (GOMES, 1932, p. 5).

Constata-se que as mudanças nos métodos didáticos em relação a uma perspectiva tradicional iniciaram-se com a influência teórica de Pestalozzi e Froebel, como se observa nos seus escritos:

Seguindo em direção de Pestalozzi e de Froebel, os modernos dão máxima importância ao conhecimento das côres, dos sons, das sensações do tacto, do movimento. Em summa, aos elementos da intuição reúnem as qualidades sensitivas, considerando os elementos activos da intuição superiores à percepção e à vontade (GOMES, 1937, p. 63). 
São esses fundamentos que também serviram de base de sustentação ao método didático descrito por esta educadora:

\begin{abstract}
Pestalozzi, considerado, em geral, como iniciador da Nova Methodologia, distinguiu-se, principalmente, pela revolução que operou nos domínios da Pedagogia e por seu devotamento à causa da educação. Nenhum educador compreendeu tão profundamente a sensibilidade infantil nem ha pregado com mais ardor as necessidades da educação. Por isto é Froebel chamado, com toda justiça, o Apóstolo da primeira infância. Herbart atribuiu grande valor aos processos aperceptivos da intuição. Com elle a Pedagogia adquire uma base scientifica (GOMES, 1937, p.62).
\end{abstract}

Argentina Gomes demonstrava ainda outra preocupação, a temporalidade, ao criticar a forma aligeirada de trabalhar os conteúdos educacionais, para ela, conhecimento que não se aprendia e nem se dominava com a rapidez desejada:

\begin{abstract}
Um alumno de inteligência regular facilmente aprende a exemplos de substantivos, parece até distinguir o abstracto do concreto, faz toda aquella classificação. Levando o mestre a supor que este ponto está preparado e que, por conseguinte, deve passar a outro. Mande o professor que esse tal menino sublinhe num ditado de quinze linhas todos os nomes que encontrar e, posso assegurar, o resultado o deixará boquiaberto, taes e tantos os erros perpetrados. E que a creança não pode aprender tudo de um jacto. Só lentamente, á força de vários exercícios e racaptulações poderá ella assimilar o aprendido e enraizar no cérebro o ensinamento do professor (GOMES, 1932, p. 6).
\end{abstract}

E, ainda, esclarece: "Outro ponto que a nosso ver ocasiona grandes dificuldades para o estudo do Português é a multiplicidade de materiais do curso primário que obriga o professor a correr pelos programas esquecendo-se, os menos práticos, de demorar nos essenciais" (GOMES, 1932, p. 6). Amparada inicialmente nas ideias de Pestalozzi e Froebel, a educadora procurou unir elementos que favorecessem o ensino para as crianças, para fazer com que os alunos aprendessem de forma suave, levando os conteúdos apreendidos para a vida prática em formação, pois entendia que "O homem não é puro espírito. Nenhum conhecimento do mundo exterior chega à sua inteligência sem que se tenha passado pelos sentidos" (GOMES, 1937, p. 62).

Observa-se que já no início da década de 1930, mesmo sem o contato com os intelectuais da Escola Nova ou com o documento do Manifesto dos Pioneiros da Educação, datado de 1932; Argentina Gomes já problematizava os métodos de ensino da Pedagogia Tradicional e a maneira como as crianças aprendiam, consoante ao que sinaliza Faria Filho: 
Assim, por variadas vias, a discussão sobre os métodos, que enfocava a questão da organização da classe, e o papel do professor como organizador e agente da instrução vão dando lugar às reflexões que acentuam a importância de prestar atenção aos processos de aprendizagem dos alunos, afirmando que o professor somente poderia ensinar bem se o processo de ensino levasse em conta os processos de aprendizagem do aluno (FARIA FILHO, 2012, p. 143).

Argentina Gomes, ainda que não disseminasse os ideais da Escola Nova no que concerne à educação pública, laica, obrigatória e gratuita (VIDAL, 2013), já tecia uma crítica enfática aos métodos de ensino adotados na década de 1930, valorizando o processo de aprendizagem do aluno, individual, específico, que levasse em consideração o contexto de vida do educando. Nessa direção, os exercícios de leitura por ela propostos, por exemplo, eram feitos de forma que os alunos soubessem o que estavam lendo e o significado de cada palavra na interface com a realidade de mundo do aluno, possibilitando-o não apenas ampliar seu arcabouço ortográfico, mas também a possibilidade de refletir esse contexto circundante:

Após algum tempo vêm os exercícios reiterados de composição, de fraseologia, pequenas historietas, leitura corrente e comentada, copias, dictados, etc... tudo o que se possa desenvolver e enriquecer o espirito da creança, aumentar-lhe o vocabulário, retificar-lhe as ideias e ampliar-lhes os horizontes (GOMES, 1932, p. 5).

O ditado, atividade característica do ensino tradicional, por exemplo, não era abandonado, mas era realizado de maneira diferente, por Argentina Gomes. Ela almejava não apenas que os alunos decodificassem e soubessem a grafia correta de cada palavra, mas investia na compreensão do significado de cada palavra, não para decorar ou memorizar a escrita da palavra, mas compreendê-la contextualizadamente. As didáticas adotadas e descritas por Argentina Gomes, disseminadas nos seus escritos, davam instruções ao professor de como este deveria ministrar suas aulas, "sem o uso de instrumentos que levassem o aluno a aprender de forma mecânica ou arbitrária" (GOMES, 1932, p. 6) e acrescentava que tais orientações poderiam ser seguidas por qualquer professor da escola primária, pois defendia o direito de toda criança ser educada de maneira prazerosa, independente de suas condições intelectuais.

Argentina Gomes se comparada a outras educadoras de seu tempo, que adotavam posturas puramente tradicionais, inovou por colaborar com reflexões 
acerca dos métodos didáticos ao problematizar, ainda no início da década 1930, os métodos tradicionais, inclusive, descrevendo metodologias interativas, inclusivas e contextualizadas, disseminando e publicando tais ideias (MENDES, 2012). Argentina Gomes, ao propalar o uso de métodos ativos e criticar a educação tradicional, adianta discussões que emergiram, mais enfaticamente, somente com o movimento da Escola Nova, que começam a chegar às instituições educativas de João Pessoa apenas uma década depois.

O Relatório de inspeção permanente do Colégio Nossa Senhora das Neves apresentado ao interventor Argemiro de Figueiredo, ainda que pioneiro na disseminação dos ideais da Escola Nova, só vai aderir a essas ideias na década de 1940:

\begin{abstract}
Com a escola nova, com os methodos de socialização do ensino, com a feição pratica dominante na moderna pedagogia, a aprendizagem normal não comporta mais o modo emprico em que é presentemente vasado em a nossa Escola Normal Official [...]. 0 governo, que tem em vista uma completa reforma na Instrucção, estou certo, tambem olhará com particular interesse para esse ramo do ensino publico. Urge a sua transformação em novos moldes, dando-se-lhe uma feição pratica que se avizinhe melhor da vida como ella é realmente vivida (ALMEIDA, 1943, p. 11)
\end{abstract}

No segundo artigo escrito por Argentina Pereira Gomes, com o título "Principios básicos do methodo didactivo", na Revista do Ensino, em 1937, no entanto, além de ela já colocar em evidência metodologias mais ativas para serem aplicadas na perspectiva da educação contextualizada, que considera os alunos em suas individualidades, desde o início da década de 1930, ela demonstrava, sete anos depois, o princípio de sua aproximação com as ideias da Escola Nova, o que se comprova no seu escrito: "Desta maneira encontra justificação a doutrina da Escola Nova no que respeita à methodologia do ensino, nesta primeira phase da vida escolar" (GOMES, 1937, p. 66). Pode-se afirmar que o movimento da Escola Nova foi apropriado por Argentina Gomes a partir da segunda metade da década de 1930, ao se preocupar com o desenvolvimento educacional da criança, adotando e disseminando didáticas de ensino que procuravam levar em consideração uma aprendizagem significativa, aprazível e contextualizada independente da classe social do aluno. 
Ao respeitar os ritmos e tempos dos alunos e considerar a compreensão crítica da realidade, Argentina Gomes se aproximava dos pressupostos da Escola Nova, que possuía como pilar a educação pública, gratuita e de qualidade para todos, considerando um ensino geral que partisse das especificidades de cada região, respeitando cada cultura e fomentando o aluno crítico capaz de intervir para melhorar o seu contexto social. Nesse viés de conhecer a realidade que envolvia os alunos, as circunstâncias históricas imbricadas na vida do docente, Argentina Gomes lecionava: "[...] As qualidades especiaes das cousas e os processos parciais são conhecidos de modo muito deficiente. Desta maneira entra justificação a doutrina da Escola Nova no que respeita á methodologia do ensino, nesta primeira phase da vida escolar" (GOMES, 1937, p. 66).

O movimento da Escola Nova ganhou notoriedade no Brasil, mais enfaticamente, apenas no final da primeira metade do século XX, trazendo renovação no ensino desde uma revisão e crítica da pedagogia tradicional, ao questionar, por exemplo, o enciclopedismo e ensejar importância às atividades dos alunos com métodos ativos, desde a adaptação do ensino às fases de desenvolvimento; colocando o aluno como centro do processo educativo (MARTINS; DUARTE, 2010). Com efeito, constata-se que Argentina Gomes era uma educadora que rompeu com práticas tradicionais do ensino formal na condição de professora, adotando métodos inovadores para a Paraíba da década de 1930, tecendo críticas pertinentes às características estáticas e mnemônicas da pedagogia tradicional. E, mesmo formada numa época marcada pela educação familiar patriarcalista que fomentava educação feminina voltada para as prendas do lar e para o matrimônio, Argentina Gomes fundamentou suas preocupações com a educação primária desde os conhecimentos de base social e psicológica, sem prescindir da reflexão acerca dos processos que envolviam o cognitivo da criança e as múltiplas formas de assimilação dos conhecimentos com amparo teórico, primeiramente, em Pestalozzi e Froebel, e, posteriormente, na Escola Nova. 


\section{Considerações finais}

A pesquisa apresentada versou acerca da biografia de Argentina Pereira Gomes, mulher educadora paraibana que atuou em importantes instituições escolares da cidade de João Pessoa — Liceu Paraibano, Escola Nossa Senhora das Neves e Grupo Escolar Epitácio Pessoa - com ênfase na sua formação e prática docente. Argentina Gomes participou da formação educacional de uma geração de crianças e adolescentes, especialmente na educação primária, ao atuar por mais de trinta anos no magistério e disseminar ideias pedagógicas e práticas didáticas que podem ser conceituadas inovadoras para a década de 1930, ao considerar o contexto paraibano caracterizado pela Pedagogia Tradicional.

Ao problematizar a formação educacional e as ideias pedagógicas que foram desenvolvidas por Argentina Gomes para que esta se constituísse uma educadora de relativa visibilidade, na memória coletiva em João Pessoa no segundo quartel do século XX, desenvolveu-se um estudo com o escopo de compreender a trajetória formativa e profissional de Argentina Pereira Gomes, na interface com os seus métodos didáticos no contexto sócio-histórico educacional das décadas de 1930.

Desde o amparo teórico na História Cultural, que ampliou a compreensão sobre fontes históricas, e da pesquisa do tipo biográfica hermenêutica, que lança lume às individualidades no imbricamento com o coletivo, ao considerar criticamente o contexto sócio-histórico e educacional; utilizou-se fontes variadas documento escolar, registro icnográfico, reportagens de revista e jornal, relatos orais -, que possibilitaram uma narrativa acerca da trajetória educativa e das ideias pedagógicas disseminadas e desenvolvidas nos anos de 1930.

Os resultados permitiram inferir que Argentina Pereira Gomes foi uma criança de classe econômica desfavorecida, que teve o privilégio de conseguir uma vaga na Escola Normal ao se mudar para a capital, aproveitando essa oportunidade para se destacar nos estudos e ser uma educadora de trabalho relativamente reconhecido na cidade de João Pessoa — PB, onde atuou por trinta anos na educação. Sua visibilidade, no entanto, não denota somente a temporalidade dedicada à educação, mas, especialmente, as suas práticas educativas que comportavam métodos diferentes dos usuais da Pedagogia Tradicional. 
Como professora em instituições escolares renomadas na cidade de João Pessoa, como o Liceu Paraibano, a Escola Normal, a Escola Nossa Senhora das Neves e o grupo Escolar Epitácio Pessoa, Argentina Gomes se apropriou e disseminou ideias de Pestalozzi, Froebel e, posteriormente, da Escola Nova, inclusive, escrevendo para revistas especializadas da área, como é caso da Revista do Ensino. Ela adotava e propagava uma nova didática alicerçada num modelo renovador de ensino que criticava a Pedagogia Tradicional, por esta ser marcada pela memorização, autoritarismo e decodificação descontextualizada que desconsidera o ritmo do aluno e seu entorno social e cultural. Além disso, estimulava uma educação dialógica, dinâmica e interativa, que se preocupa com a aprendizagem significativa, ao levar em consideração as individualidades dos alunos e as especificidades sociais do mundo que os cercam.

Importa inferir que a pesquisa do tipo biográfica possui a limitação de impossibilitar generalizações, por tratar de uma única vida e suas singularidades. No entanto, contribui para preservar a história e memória da educação, em especial, ao valorizar e lançar luz na participação feminina na História da Educação na Paraíba.

\section{Referências}

ALMEIDA, J. S. Ler as letras: por que educar meninas e mulheres? São Bernardo do Campo: Universidade Metodista de São Paulo: Campinas: Autores Associados, 2007.

ALMEIDA, M. M. Relatório de inspeção permanente do Colégio Nossa Senhora das Neves. Escola Nossa Senhora das Neves. Escolas Extintas da primeira região. 1943.

BURKE, P. A escrita da História: novas perspectivas. Tradução de Magda Lopes. São Paulo: Editora da Universidade Estadual Paulista, 1992.

BURKE, P. O que é história cultural? Trad. Sergio Goes de Paula. 2. ed. Rio de Janeiro: Jorge Zahar Editora, 2008.

BURKE, P. A Escola dos Annales (1929-1989): a revolução francesa da historiografia. Trad. Nilo Odalia. 2 ed. São Paulo: Editora da Unesp, 2010.

CHARTIER, R. A bistória cultural: entre práticas e representações. Trad. Maria Manuela Galhardo. Lisboa: Difel, 1988.

DIECKMAN, M. M. Entrevista concedida a Márcia Cristiane Ferreira Mendes. João Pessoa, 02 jun. 2009. 
DOSSE, F. O desafio biográfico: escrever uma vida. 2. Ed. São Paulo: Editora da Universidade de São Paulo, 2015.

FALCI, M. K. Mulheres do sertão nordestino. In: PRIORE, M. (Org.). História das mulheres no Brasil. 4. ed. São Paulo: Contexto, 2001. p. 241-77.

FARIA FILHO, L. M. Instrução Elementar no Século XIX. In: LOPES, E. M. T.; FARIA FILHO, L. M.; VEIGA, C. G. (orgs). 500 anos de educaşão no Brasil. 4 ed. Belo Horizonte: Autêntica, 2012. p. 135-150.

FIALHO, L. M. F.; QUEIROZ, Z. F. Maria Neli Sobreira: história e memória da educação em Juazeiro do Norte. Educar em Revista, Curitiba, Brasil, v. 34, n. 70, p. 67-84, jul./ago. 2018.

FIALHO, L. M. F.; SÁ, É. C. Educadora Henriqueta Galeno: Trajetória de uma literata feminista (1887-1964). História da Educação, Porto Alegre, v. 22 n. 55 maio/ago. 2018. p. 169-188.

FREITAS, M. C.; BICCAS, M. S. História social da educação no Brasil (1926-1996). São Paulo: Cortez, 2009.

GILES, T. R. História da educação. Trad. Roberto Leal. São Paulo: EPU, 1987

GOMES FILHO, J. P. Entrevista concedida a Márcia Cristiane Ferreira Mendes. João Pessoa, 02 jan. 2009.

GOMES, A. P. Principios basicos do methodo didactivo. Revista do Ensino: Orgam da Directoria do Ensino Primario, Anno 1, n. 1, p. 5-6, 1932.

GOMES, A. P. Lingua materna. Revista do Ensino: Orgam da Directoria do Ensino Primario. Anno V, n. 14, p. 61-67, 1937.

HOLANDA, F.; MEIHY, J. C. S. B. História oral: como fazer, como pensar. São Paulo: contexto, 2007.

JORNAL A UNIÃO. 11 de Abril de 1962, p. 3-6.

LE GOFF, J. História e memória. 5. ed. Campinas: FGV, 2003.

LEITE, M. L. M. Outra face do feminismo: Maria Lacerda de Moura (1887-1945). São Paulo: Editora Ática, 1984.

LOPES, T. M. R.; FIALHO, L. M. F.; MACHADO, C. J. S. Mulheres educadoras do cariri cearense no fomento à inclusão (1970-1990). Linguagens, Educação e Sociedade, Teresina, Ano 23, n. 38, jan./jul. 2018.

LORIGA, S. O pequeno X: da Biografia à História. Belo Horizonte: Autêntica, 2011.

LOURO, G. L. Mulheres na sala de aula. In: PRIORE, M. (Org.). História das mulheres no Brasil. 4. ed. São Paulo: Contexto, 2001. p. 443-481.

LUCENA, H. L. Entrevista concedida a Márcia Cristiane Ferreira Mendes. João Pessoa, 04 mai. 2009. 
MARTINS, L. M.; DUARTE, N. (orgs). Formação de professores: limites contemporâneos e alternativas necessárias [online]. São Paulo: Editora UNESP; São Paulo: Cultura Acadêmica, 2010. 191 p. Disponível em: <http://books.scielo.org/id/ysnm8/pdf/martins9788579831034-05.pdf>. Acesso em: 12 jan. 2019.

MATOS, M. I. S. Sorria: mulher, publicidade e dentes. In: SEMINÁRIO INTERNACIONAL FAZENDO GÊNERO: DIÁSPORAS, DIVERSIDADES E DESLOCAMENTOS, 2010, Florianópolis. Anais... Disponível em: <http://www.fazendogenero.ufsc.br/9/resources/anais/1278004976_ARQUIVO_MariaI zilda.pdf>. Acesso em: 02 mai. 2013.

MELO, L. de A. Entrevista concedida a Márcia Cristiane Ferreira Mendes. João Pessoa, 07 mai. 2009.

MELO. J. O. de A. Entrevista concedida a Márcia Cristiane Ferreira Mendes. João Pessoa, 10 mar. 2008.

MENDES, M. C. F. Memórias e Práticas Educacionais da Educadora Argentina Pereira Gomes: o seu legado no cenário educativo da Paraíba (1916 -1962). 2012. 129 f. Dissertação (Mestrado em Educação) — Universidade Federal da Paraí-ba, João Pessoa, 2012.

NÓVOA, A. (org). Vida de professores. Trad. Maria dos Anjos Caseiro e Manuel Figueiredo Ferreira. Lisboa: Porto Editora, 1995.

NUNES, M. L. S. Uma página feminina: vozes de mulheres paraibanas na década de 1930. In: CONGRESSO BRASILEIRO DE HISTÓRIA DA EDUCAÇÃO: O ENSINO E A PESQUISA EM HISTÓRIA DA EDUCAÇÃO, 5., 2008, Aracaju/SE. Anais... Disponível em: <http://www.sbhe.org.br/novo/congressos/cbhe5/pdf/580.pdf>. Acesso em: 12 jan. 2014.

OLIVEIRA, A. F. B. O que se Preservou em João Pessoa ou de Quando a arte e a Arquitetura definem o Patrimônio Cultural de uma cidade. São Paulo: Cordiz: Comunicação, Modernidade e Arquitetura, n. 8, jan./jun. pp. 367-396, 2012. Disponível em: $<$ http://revistas.pucsp.br/index.php/cordis/article/view/12934/9402>. Acesso em: < 16 de jan 2019.

OLIVEIRA, I. B. Façamos a família à nossa imagem: a construção de conceitos de família no Recife moderno (décadas de 1920 e 1930). 348f. Tese (Doutorado em História). Programa de Pós-Graduação em História. Universidade Federal de Pernambuco, Recife, 2002.

PEREGRINO, A. de M. Entrevista concedida a Márcia Cristiane Ferreira Mendes. João Pessoa, 07 mai. 2009. João Pessoa, 02 jun. 2009.

PINHEIRO, A. C. F. A era das Escolas Rurais Primárias na Paraíba (1935 a 1960). In: MACHADO, C. J. S. SCOCUGLIA, A. C. Pesquisa bistoriográfica da educaşão brasileira. Campinas: Autores Associados, 2006, p. 133159.

SANTOS, T. M. Magistério em Declínio: histórias e memórias de ex-alunas do magistério do colégio Nossa Senhora das Neves (1970). João Pessoa: UFPB, 2009. 
SAVIANI, D. História das ideias pedagógicas no Brasil. 2. ed. Campinas: Autores Associados, 2008.

SAVIANI, D. Estado e políticas educacionais na história da educação brasileira. Vitória: EDUFES, 2011.

SILVA, C. B. Entre o bem e o mal: Discursos de moralidades na Imprensa Campinense (19091939). 161f. Dissertação (Mestrado em Ciências da Sociedade) — Universidade Estadual da Paraíba, Campina Grande, 2006.

VASCONCELOS, L. M; FIALHO, L. M. F; MACHADO, C. J. S. Educação, gênero e higienismo nos anúncios publicitários da Paraíba durante a Primeira República. Cadernos de História da Educação (Online), Uberlândia, v. 16, p. 451-473, 2017. Disponível em: <http://www.seer.ufu.br/index.php/che/article/view/39598>. Acesso em: 11 fev. 2019.

VEYNE, P. M. Como se escreve a História: Foucault revoluciona a História. Trad. Alda Baltar e Maria Auxiliadora Kneipp. 4 ed. Brasília: UnB, 2008.

VIDAL, D. G. 80 anos do Manifesto dos Pioneiros da Educação Nova: questões para debate. Educ. Pesqui., São Paulo, v. 39, n. 3, p. 577-588, jul./set. 2013. Disponível em: <http://www.scielo.br/pdf/ep/v39n3/aop1177.pdf>. Acesso em: 11 mar. 2019. 